\title{
Balneoterapinin Fibromiyalji Hastalarında Ağrı ve Yaşam Kalitesine Etkisi
}

\author{
The Effect of Balneotherapy On Pain and Quality of Life in Patients with Fibromyalgia \\ Ahmet Karadağ ${ }^{1}$, Muhammet Canbaş ${ }^{1}$, Mesut Parlak ${ }^{2}$ \\ ${ }^{1}$ Cumhuriyet Üniversitesi Tıp Fakültesi, Fiziksel Tıp ve Rehabilitasyon Anabilim Dalı, Sivas \\ ${ }^{2}$ Numune Hastanesi, Farmakoloji Bölümü, Sivas
}

\section{ÖZET}

Amaç: Bu çalışmanın amacı Balneoterapinin (BT) fibromiyalji sendromu (FMS) olan hastalarda ağrı ve yaşam kalitesi üzerine etkisini araştırmaktır.

Gereç ve Yöntem: Çalışmaya; 18-65 yaş arasında, 2010 American College of Rheumatology kriterlerine göre FMS tanısı alan ve çalışmayı kabul eden, bilinen metabolik ve psikiyatrik hastalığı olmayan ve son 1 ay içinde yeni bir ilaç kullanmamış 98 kadın hasta dahil edildi. Hastaların sosyodemografik özellikleri kaydedildi. Hastalar günde 1 defa olmak üzere her gün 20 dakika olacak şekilde toplam 21 seans BT aldı. Tüm hastalar tedavi öncesi ve sonrasında Fibromiyalji Etki Anketi (FEA) ve Görsel Analog Skala (GAS) ile değerlendirildi.

Bulgular: Çalışmaya alınan 98 FMS hastasının ortalama yaşı $53.04 \pm 10.3$ yıl, ortalama vücut kitle indeksi $29.06 \pm$ $5.9 \mathrm{~kg} / \mathrm{m} 2$ ve hastalık süresi ortalama $54.91 \pm 59.5$ ay olarak belirlendi. FMS'li hastaların tedavi öncesi ve tedavi sonrası değerlendirilen GAS ve FEA skorları arasındaki istatistiksel olarak anlamlı farklıık vardı $(p=0.01)$. FEA skorlarındaki azalma sigara içmeyen hastalarda daha fazlaydı $(p<0.05)$.

Sonuç: FMS'li hastalarda BT sonrasında GAS değerlerinde ve FEA skorlarında anlamlı derecede azalma vardı. Bununla birlikte yaşam kalitesindeki artış sigara içmeyen FM'li hastalarda sigara içen FM'li hastalara oranla daha fazladır.

Anahtar kelimeler: Balneoterapi, fibromiyalji, tedavi, ağrı.

\section{ABSTRACT}

Aim: The aim of this study was to investigate effect of balneotherapy (BT) on pain and quality of life in patients with fibromyalgia (FMS).

Material and Methods: The study included 98 women without known metabolic or psychiatric disorder and history of new medication within prior month who were diagnosed as primary fibromyalgia according to 2010 American College of Rheumatology (ACR) criteria and accepted to participate to the study. The sociodemographic characteristics were recorded for all patients. All patients received 21 consecutive sessions of balneotherapy (20 minutes per day). The patients were assessed by Fibromyalgia Impact Questionnaire (FIQ) and Visual Analog Scale (VAS) before and after therapy.

Results: The mean age of the all patients was $53.04 \pm 10.3$ years, the mean body mass index was $29.06 \pm 5.9 \mathrm{~kg} / \mathrm{m} 2$, and the mean disease duration was $54.91 \pm 59.5$ months. In patients with FMS, there were significant differences between VAS and FIQ scores assessed before and after BT $(p=0.01)$. Also, the extent of decrease in FIQ score was greater in non-smokers than smoker FM patients $(p<0.05)$. Conclusion: In patients with FM, there was a significant difference in VAS scores following BT. Moreover, there was also a significant difference in FIQ scores. However, the improvement in quality of life after BT was greater in nonsmoker FM patients when compared to smoker FM patient.

Key words: Balneotherapy, fibromyalgia, treatment, pain.

Gönderme tarihi / Received: 07.02.2018 Kabul tarihi / Accepted: 27.02.2018

İletişim: Ahmet Karadağ, Cumhuriyet Üniversitesi Tıp Fakültesi, Fiziksel Tıp ve Rehabilitasyon Anabilim Dalı, Sivas Tel: 05065335456 E-posta: dr_ahmetkaradag@hotmail.com 


\section{GiRiş}

Fibromiyalji sendromu (FMS), yaygın vücut ağrısı, tutukluk ve hassas noktaların varlığı ile karakterize etyolojisi bilinmeyen bir kas iskelet sistemi hastalığıdır (1). FMS'de ağrıya ek olarak yorgunluk, sabah tutukluğu, depresyon, uyku bozukluğu başta olmak üzere çeşitli somatik ve psikolojik semptomlar da eşlik etmektedir (2). Yapılan klinik çalışmalarda, FMS'nin etyolojisi bilinmemekte ve patofizyolojisi net olarak açıklanamamaktadır. Bununla birlikte etyopatogenezde genetik, çevresel, immünolojik faktörler, periferik ve santral mekanizmaların rol oynadığı düşünülmektedir $(3,4)$.

Etyoloji net olarak belli olmadığından dolayı FMS için standart bir tedavi rejimi bulunmamaktadır. Mevcut kanıtlar, FMS'de tek bir tedavi seçeneğinin etkili olmadığını ve multidisipliner bir yaklaşımın gerektiğini belirtmektedir. FMS tedavisinde farmakolojik ve farmokolojik olmayan tedavi yaklaşımları hastaların semptomlarını azaltmakta ve fonksiyonel kapasitelerini artırmaktadır. FMS tedavisinde analjezikler ve non-steroid antiinflamatuar ilaçların tek başına etkinliğini gösteren çok az veri vardır (5). Antidepresan ilaçlar FMS'de en sık kullanılan ilaçlardır. Antikonvülzanlar arasından pregabalin ve gabapentin FMS tedavisinde sık kullanılan ajanlardır. FMS tedavisinde non-farmakolojik tedavi yöntemleri hastanın fiziksel fonksiyonlarını ve aktivite düzeylerini artırmayı hedeflemektedir. Etkinliği kanıtlanmış yöntemler arasında hasta eğitimi, bilişsel davranışçı terapi, egzersiz ve tamamlayıcı tıp uygulamaları bulunmaktadır. Bunlara ek olarak FMS tedavisinde fizik tedavi ajanları, hidroterapi ve balneoterapi (BT) gibi yöntemler de sıklıkla kullanılmaktadır (6).

Balneoterapi (BT), termal ve/veya mineralli suların, peloidlerin ve gazların çeşitli yöntemler ile belli zaman aralığında tekrarlanarak kür tarzında uygulandığı bir tedavi yöntemidir (7). Kas iskelet sistemi ağrılarını tedavi etmek için farklı kültürlerde yıllardır kullanılmaktadır. Bu yüzden
FMS tedavisinde doğal bir tedavi yöntemi olarak kullanılabilmektedir (8). BT'nin FMS semptomları üzerine anlamlı ve olumlu etkilerinin olduğu çalışmalarda gösterilmiştir. Fakat FMS'li hastalarda BT'nin ağrı ve yaşam kalitesi üzerine etkisini araştıran sınırlı sayıda klinik çalışma bulunmaktadır. Yapılan bu klinik çalışmalarda BT'nin etkisi genellikle farklı bir tedavi metodu ile kombine edilerek değerlendirilmiştir. Bu çaIışmanın amacı balneoterapinin FMS'li hastalarda ağrı ve yaşam kalitesi üzerine etkisini araştırmaktır.

\section{GEREÇ VE YÖNTEM}

Çalışmaya 2010 American College of Rheumatology (ACR) tanı kriterlerine göre FMS tanısı almış 100 kadın hasta dahil edildi (9). İki katııımcı kendi isteği ile çalışmadan ayrıldı. Çalışma 98 FMS'li hasta ile tamamlandı. Çalışmaya 18-65 yaş arasında ACR 2010 tanı kriterlerine göre FMS tanısı alan ve çalışmayı kabul eden ve son 1 ay içinde yeni bir ilaç kullanmamış kadın hastalar dahil edildi. İnflamatuar romatizmal hastalığı olanlar, FMS dışında kas iskelet sistemi hastalığı olanlar, bilinen pulmoner, kardiyovasküler, hematolojik, psikiyatrik, metabolik ve endokrin bozukluğu olanlar, malignitesi olan, radyoterapi veya kemoterapi alan hastalar ile gebe veya laktasyonda olan bireyler dahil edilmedi.

Tüm katılımcılardan tam kan sayımı, eritrosit sedimentasyon hızı, C-reaktif protein, karaciğer ve böbrek fonksiyon testleri, kan şekeri ve elektrolitleri, tiroid fonksiyon testleri ve tam idrar analizi yapıldı. Bu testlerin herhangi birinde anormallik saptanan hastalar çalışma dışı bırakıldı. Hastaların yaş, ilaç kullanım öyküsü, sigara alışkanlığı, hastalık süresi, boy ve kilosu kaydedildi.

FMS'li hastalar toplam 21 seans BT (1 seans/20dk/gün) aldı. BT seansları sırasında hastalar sadece terapötik havuzda dinlenip rahatladılar. BT için sıcaklığı $40^{\circ} \mathrm{C}$ olan ve kalsiyum 
(655 mg/L) ve bikarbonattan (2003 mg/L) zengin termal su kullanıldı. Tüm hastaların ağrı ve fonksiyonel durumları tedavi öncesi ve sonrasında Fibromiyalji Etki Anketi (FEA) ve Görsel Analog Skala (GAS) ile değerlendirildi.

Çalışmaya alınmadan önce tüm katılımcılar çalışma hakkında bilgilendirildi ve aydınlatılmış onam formu alındı. Bu çalışma için, Cumhuriyet Üniversitesi Tıp Fakültesi Klinik Araştırmalar Etik Kurulunun onayı alındı ve çalışma, Helsinki Deklarasyonu'na uygun olarak yapıldı.

Fibromiyalji Etki Anketi (FEA): Hastaların fonksiyonel durum değerlendirmeleri FEA anket formu kullanılarak yapıldı. FEA, FMS tanılı hastaların durumlarını ve sonuçlarını takip eden 10 maddeden oluşan bir kendini değerlendirme ölçeğidir. İlk madde, her biri 0-3 arası puanlanan 10 sorudan oluşmuştur. İkinci ve üçüncü maddelerde "hastalıktan etkilenme" ve "işe gidememe" tespiti için gün işaretlemesi istenir. FEA fiziksel fonksiyon, kendini iyi hissetme hali, işe gidememe, işte zorlanma, ağrı, yorgunluk, sabah yorgunluğu, tutukluk, anksiyete ve depresyon olmak üzere 10 ayrı özelliği ölçer. Puan aralığı 0-100'dür. Ülkemizde geçerlilik ve güvenilirlik çalışması, Sarmer ve ark.(10) tarafından yapılmıştır.

Görsel Analog Skala (GAS): Hastalarda tüm vücut ağrı şiddetini sorgulamak için VAS kullanıldı. $10 \mathrm{~cm}$ uzunluğunda olan bir cetvel üzerinde 0 ağrı yok durumunu gösterirken, 10 en şiddetli ağrıyı göstermektedir. Hastalardan 10 cm'lik çizgi üzerinde ağrılarını ifade eden kısmı işaretlemeleri istendi.

\section{1. İstatiksel Analiz}

Elde edilen veriler değerlendirilirken, istatistiksel analizler için SPSS (Statistical Package for Social Sciences) for Windows 22.0 programı kullanıldı. Verilerin değerlendirilmesinde parametrik test varsayımları yerine getirildiğinde bağımsız gruplarda iki ortalama arasındaki farkın önemlilik testi, eşleştirilmiş iki grup arasındaki farkların testi (paired-samples "t" testi), varyans analizi, Tukey testi ve pearson korelasyon uygulandı. Parametrik test varsayımları yerine getirilmediğinde Wilcoxon, Man-Whitney U testi, Kruskal-Wallis testi ve spearmen testi kullanımıştır. Verilerimiz tablolarda birey sayısı, yüzdesi ve ortalama \pm standart sapma şeklinde belirtilip yanılma düzeyi 0.05 olarak alındı.

\section{BULGULAR}

98 FM'li hasta çalışmayı tamamladı. Çalışmaya katılan FMS'li hastaların klinik ve demografik özellikleri Tablo 1'de gösterilmiştir.

Tablo 1. FMS hastalarının klinik ve demografik özellikleri

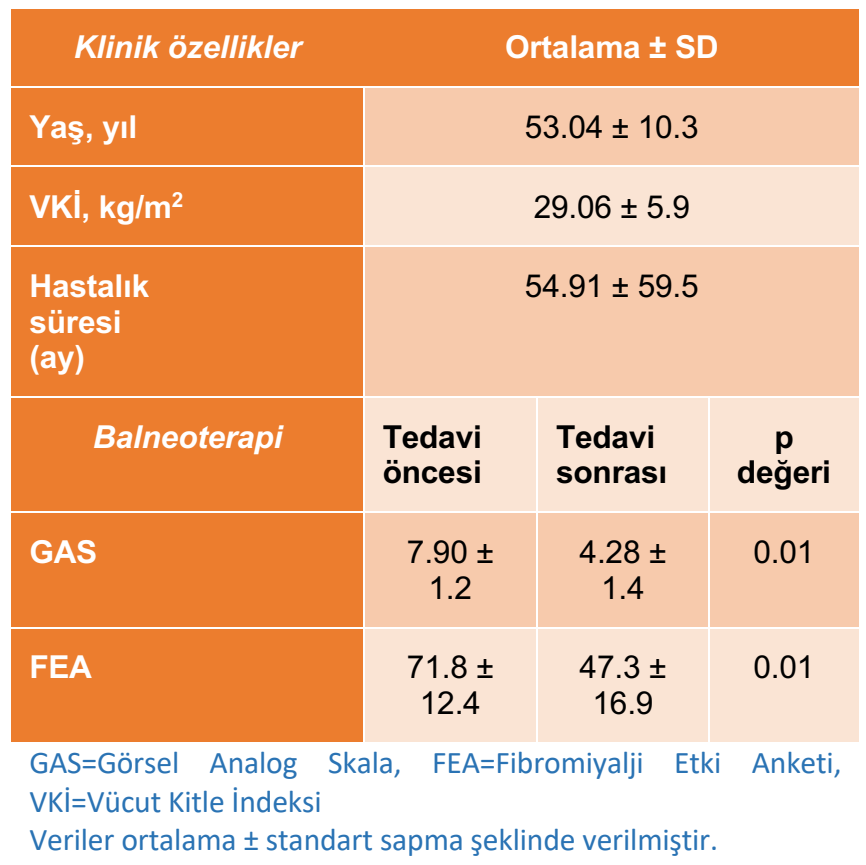

FMS hastalarında BT öncesi ve sonrası değerlendirilen ortalama GAS skorları ve ortalama FEA arasında istatistiksel olarak anlamlı farklılık vardı $(p<0.05)$. FMS hastaları, sigara içme durumu yönünden iki gruba ayrıldığında, ortalama FEA skorlarındaki azalma sigara içmeyen FMS'li hastalarda daha fazlaydı. FEA skorlarındaki azalma yönünden gruplar arasında istatistiksel olarak anlamlı fark vardı $(p=0.01)$. GAS 
değerlerindeki azalma yönünden sigara içen ve sigara içmeyen FMS'li hastalar arasında istatiksel olarak anlamlı farklılık yoktu $(p>0.05)$.

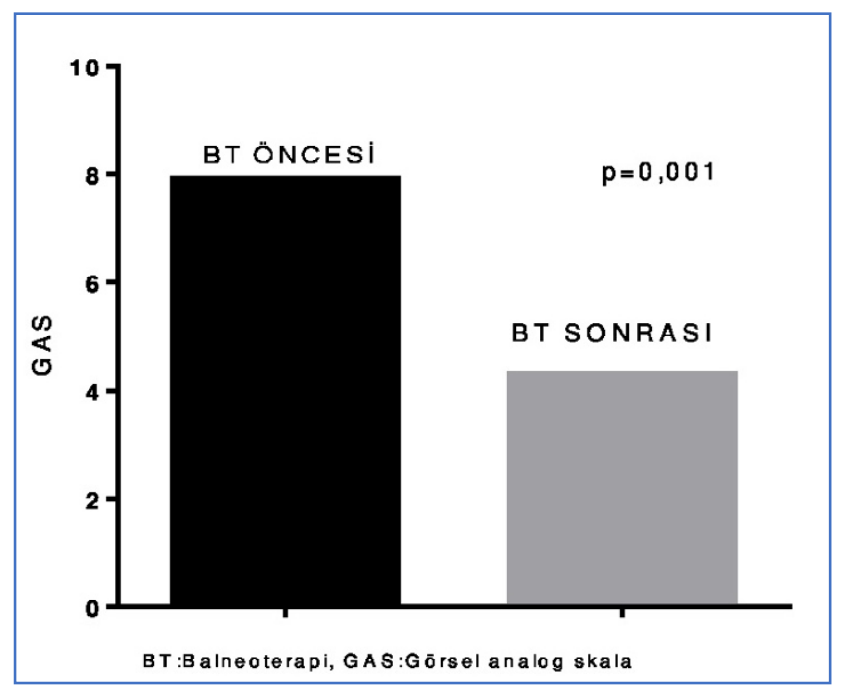

Şekil 1. BT öncesi ve sonrası GAS değerleri

\section{TARTIŞMA}

FMS'li hastalarda ağrı ve yaşam kalitesi üzerine BT'nin etkisini araştırdığımız bu çalışmada FMS'li hastaların BT sonrasında GAS değerlerinde istatistiksel olarak anlamlı azalmanın olduğunu bulduk. Ayrıca BT sonrası FMS'li hastalarda FEA skorlarında da istatistiksel olarak anlamlı azalma bulduk. Bununla birlikte FEA skorlarındaki azalma sigara içmeyen hastalarda sigara içen hastalardan daha fazlaydı. Çalışmamızın bu bulguları daha önce yapılan klinik çalışmalar ile uyumludur $(11,12)$. Literatürden farklı olarak FMS'li hastaların ağrı skorları ile sigara kullanımı arasında ilişki bulmadık (13).

FMS'li hastalarda yaşam kalitesinin olumsuz yönde etkilendiği bilinmektedir (14). FMS'deki yaygın ağrı semptomu FMS'li hastalarda yaşam kalitesindeki bozulmanın ana nedenlerinden biridir. FMS tedavisinde ana amaç ağrının azaltılması ve yaşam kalitesinin arttırılmasına yöneliktir. FMS tedavisinde kullanılan farmakolojik ajanlar hastalığın tedavisinde yetersiz kalabilmektedir. Bu nedenle FMS tedavisinde farmakolojik tedaviye ek olarak tamamlayacı tedavi- lerde yaygın olarak tercih edilmektedir (15). Daha önce yapılan klinik çalışmalarda BT'nin FMS tedavisinde etkili olduğunu bildirilmektedir (16-18). Balneoterapinin etkisinin beta endorfin ve kortizol düzeylerinde artışa neden olması, interlökin 1, prostaglandin E2 ve lökotrien B4 düzeylerini düşürdüğü ve antioksidan sistem üzerine olumlu etkisinden dolayı kaynaklandığı gibi farklı mekanizmalar ileri sürülmüştür (11, 19-21).

Koçyiğit ve ark.'nın yaptıkları bir çalışmada FMS'li hastalara eğitim verdikten sonra bir gruba ek olarak BT uygulanmış ve BT alan grupta FEA ve GAS değerlerinde azalmanın sadece eğitim alan gruba oranla daha anlamlı olduğunu bulunmuştur (22).

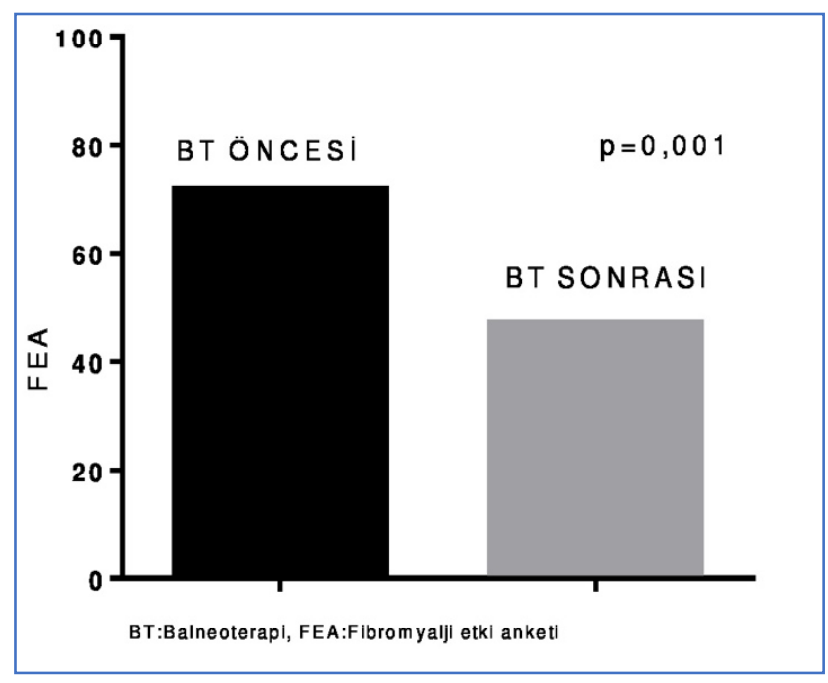

Şekil 2. BT öncesi ve sonrası FEA skorları

Benzer şekilde Evcik ve ark. (23) ile Dönmez ve ark. (24) yaptıkları klinik çalışmalarda, BT uygulanan FMS'li hastalarda GAS değerleri ve FEA skorlarında anlamlı iyileşmeler tespit etmişlerdir. Fioravanti ve ark. (25) FMS'li hastalar ile yaptığı çalışmada, hastalar BT sonrası 16 hafta boyunca takip edilmiş ve tedavinin etkisinin devam ettiğini göstermişlerdir. Bizim çalışmamızda daha önce yapılan klinik çalışmalarda olduğu gibi BT alan FMS hastalarında GAS ve FEA değerlerinde anlamlı düzeyde iyileşmeler saptanmıştır. 
FMS etyolojisinde suçlanan nedenlerden biri olan kas kan akımında azalma ve mikrosirkülasyonda bozukluk sonucu oluşan hipoksidir (26). Sigara mikrosirkülasyonu bozarak FMS semptomlarını şiddetlendirebilir. Sigara kullanımının kronik bel ve baş ağrısı ile FMS'deki kronik ağrı için risk faktörü olduğu bilinmektedir $(27,28)$. Sigara kullanımının FMS'li hastalarda ağrı ve yaşam kalitesini olumsuz yönde etkilediğini belirten klinik çalışmalar mevcuttur (29). Bizim çalışmamızda benzer şekilde sigara kullanan FMS'li hastalarda BT'den sonra yaşam kalitesinde iyileşme sigara kullanmayan hastalara oranla daha azdı. Sigara kullanımı serbest radikal üreterek oksidatif strese neden olmaktadır. Fazla miktarda oksidatif stres, BT'nin antioksidan etki kapasitesini aşarak kas yorgunluğuna ve kas liflerinde hasara neden olabilmektedir (30). Sigara kullanımının fiziksel performansı azaltabileceği ve yaşam kalitesini etkilediğini düşünmekteyiz. Literatürden farklı olarak sigara kullanan FMS'li hastalar ile kullanmayan hastalar arasında ağrı düzeyleri arasında fark yoktu. Bu klinik iyileşmenin FMS'li hastalarda BT'nin serum beta endorfin ve kortizol düzeyini artırabileceğinden dolayı kaynaklandığını düşünmekteyiz $(20,22,31)$

Çalışmamızın bazı kısıtııkları mevcuttu. Öncelikle kontrol grubunun olmaması ve çalışmaya sadece bayan hastaların alınması en temel limitasyondur. Ayrıca hastaların tedavi sonrasında uzun dönem klinik takiplerinin yapılmaması, BT'nin etki mekanizmasını açıklayacak biyokimyasal parametrelerin gösterilmemesi ve hastaların BT merkezinde yatarak tedavi almaları nedeniyle günlük rutin yaşamlarından uzaklaşarak farklı bir ortamda bulunmaları diğer limitasyonlardır.

Sonuç olarak FMS tedavisinde temel hedef ağrının azaltılarak yaşam kalitesinin arttırılmasıdır. Balneoterapi, FMS tedavisinde etkili farmakolojik olmayan bir tedavi yöntemidir. FMS'li hastalarda balneoterapinin etkinliğini değerlendiren daha geniş hasta popülasyonunu içeren, daha uzun takip süresi olan ve BT'nin etki mekanizmasını açıklamaya yönelik ileri klinik çaıışmalara intiyaç vardır.

\section{KAYNAKLAR}

1. Bellato $E$, Marini E, Castoldi F, Barbasetti $\mathrm{N}$, Mattei L, Bonasia DE, et al.

Fibromyalgia syndrome: etiology, pathogenesis, diagnosis, and treatment. Pain Research and Treatment 2012;426130.

2. Theoharides TC, Tsilioni I, Arbetman L, Panagiotidou S, Stewart JM, Gleason RM, et al. Fibromyalgia syndrome in need of effective treatments. J Pharmacol Exp Ther 2015;355:255-263.

3. Dadabhoy D, Clauw DJ. Therapy insight: fibromyalgia a different type of pain needing a different type of treatment. Nat Clin Pract Rheumatol 2006;2:364-72.

4. Albrecht PJ, Rice FL Fibromyalgia syndrome pathology and environmental influences on afflictions with medically unexplained symptoms. Rev Environ Health. 2016;31:281-94

5. Goldenberg DL, Burckhardt C, Crofford L. Management of fibromyalgia syndrome. JAMA: the Journal of the American Medical Association 2004; 292: 2388-95

6. Semiz EA, Hizmetli S, Semiz M, Karadağ A, Adalı M, Tuncay MS et al. Serum cortisol and dehydroepiandrosteronesulfate levels after balneotherapy and physical therapy in patients with fibromyalgia. Saudi Med J. 2016;37:54450

7. Bender T, Bariska J, Vághy R, Gomez R, Imre Kovács. Effect of balneotherapy on the antioxidant system--a controlled pilot study. Arch Med Res. 2007;38:86-9

8. Ablin JN, Häuser W, Buskila D. Spa treatment (balneotherapy) for fibromyalgia-a qualitative-narrative review and a historical perspective. Evid Based Complement Alternat Med. 2013;2013:63

9. Wolfe F, Clauw DJ, Fitzcharles MA, Goldenberg DL, Katz RS, Mease P et al. 
The American Collage of Rheumatology Preliminary Diagnostic Criteria for Fibromyalgia and Measurement of Symptom Severity. Arthritis Care \& Research 2010; 62:600-610.

10. Sarmer S, Ergin S, Yavuzer G. The validity and reliability of the Turkish version of the Fibromyalgia Impact Questionnaire. Rheumatol Int 2000;20:912.

11. Falagas ME, Zarkadoulia E, Rafailidis PI. The therapeutic effect of balneotherapy: evaluation of the evidence from randomised controlled trials. Int $\mathrm{J}$ Clin Pract 2009;63:1068-84.

12. McVeigh JG, McGaughey $H$, Hall M, Kane $P$. The effectiveness of hydrotherapy in the management of fibromyalgia syndrome: a systematic review. Rheumatol Int 2008;2:119-30

13. Weingarten TN1, Podduturu VR, Hooten WM, Thompson JM, Luedtke CA, Oh TH. Impact of tobacco use in patients presenting to a multidisciplinary outpatient treatment program for fibromyalgia. Clin J Pain. 2009;25:39-3

14. Campos R, Vázquez M. Health-related quality of life in women with fibromyalgia: clinical and psychological factors associated. Clinical Rheumatology 2012;31:347-55

15. Ozkurt S, Dönmez A, Zeki Karagülle M, Uzunoğlu E, Turan M, Erdoğan N.

Balneotherapy in fibromyalgia: a single blind randomized controlled clinical study. Rheumatol Int. 2012;32:1949-54

16. Buckhardt CS, Goldenberg D, Crofford L, Gerwin R, Gowens S, Jackson K, et al. Guideline for the management of fibromyalgia syndrome pain in adults and children. Glenview (IL): American Pain Society 4 th ; 2005. $109 \mathrm{p}$.

17. Carville SF, Arendt-Nielsen L, Bliddal $H$, Blotman F, Branco JC, Buskila D, et al. EULAR evidence based recommendations for the management of fibromyalgia syndrome. Ann Rheum Dis 2008; 67:53641.
18. Ha "user Winfried, Kati Thieme B, Dennis C, Turk C. Guidelines on the management of fibromyalgia syndrome-A systematic review. Eur J Pain 2010;14:510.

19. Bellometti S, Galzigna L. Function of the hypothalamic adrenal axis in patients with fibromyalgia syndrome undergoing mudpack treatment. Int J Clin Pharmacol Res 1999;19:27-33.

20. Odabasi E, Turan M, Erdem H, Tekbas F. Does mud pack treatment have any chemical effect? A randomized controlled clinical study. J Altern Complement Med 2008;14:559-65.

21. Bender T, Bariska J, Vághy R, Gomez R, Imre Kovács. Effect of balneotherapy on the antioxidant system-a controlled pilot study. Arch Med Res 2007;38:86-9

22. Koçyiğit BF, Gür A, Altındağ Ö2, Akyol A, Gürsoy S. Comparison of education and balneotherapy efficacy in patients with fibromyalgia syndrome: A randomized, controlled clinical study. Agri 2016;28:728.

23. Evcik D, Kızılay B, Gökçen E. The effects of balneotherapy on fibromyalgia patients. Rheumatol Int 2002;22:56-9.

24. Dönmez A, Karagülle $M Z$, Tercan $N$, Dinler $M$, Işsever $H$, Karagülle $M$, Turan M. SPA therapy in fibromyalgia: a randomised controlled clinic study. Rheumatol Int. 2005;26:168-72.

25. Ablin JN, Häuser W and Buskila D. Spa Treatment (Balneotherapy) for Fibromyalgia-A Qualitative-Narrative Review and a Historical Perspective. Evidence-Based Complementary and Alternative Medicine. 2013;2013:63805026.

26. Morf S, Amann-Vesti B, Forster A, Franzeck UK, Koppensteiner R, Uebelhart $\mathrm{D}$, et al. Microcirculation abnormalities in patients with fibromyalgia - measured by capillary microscopy and laser fluxmetry. Arthritis Res Ther 2005;7:209-16.

27. Shiri R, Karppinen J, Leino-Arjas $P$, Solovieva S, Viikari-Juntura E. The 
association between smoking and low back pain: a meta-analysis. Am J Med 2010;123:7-35.

28. Orhurhu VJ, Pittelkow TP, Hooten WM. Prevalence of smoking in adults with chronic pain. Tob Induc Dis. 2015;17:13-7.

29. Goesling J, Brummett CM, Meraj TS, Moser SE, Hassett AL, Ditre JW. Associations Between Pain, Current Tobacco Smoking, Depression, and Fibromyalgia Status Among Treatment-
Seeking Chronic Pain Patients. Pain Med 2015;16:1433-442

30. Ergin Ç, Yurdalan SU, Demirbüken İ, Zengin O. Fatigue and Physical Activity Levels of Smoking and Non-smoking Healthy Sedentary Individuals. Clin Exp Health Sci 2016;6:51-5.

31. Pineda JO, Oberman LM. What Goads Cigarette Smokers to Smoke? Neural Adaptation and Mirror Neuron System. Brain Research. 2006;1121:128-35. 